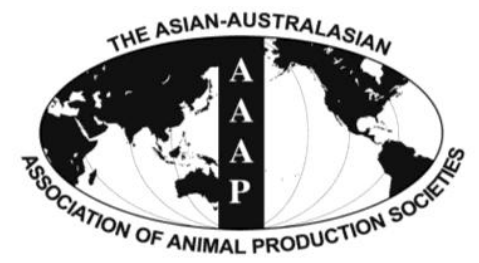

Asian-Aust. J. Anim. Sci.

Vol. 25, No. 5 : 708 - 716

May 2012

www.ajas.info

http://dx.doi.org/10.5713/ajas.2011.11246

\title{
Red Deer Antler Extract Accelerates Hair Growth by Stimulating Expression of Insulin-like Growth Factor I in Full-thickness Wound Healing Rat Model
}

\author{
ZhiHong Yang ${ }^{1, a}$, LiJuan Gua ${ }^{\text {a }}$ DongLiang Zhang, Zheng Li, JingJie Li, MiRa Lee, \\ Chun Yan Wang, Zhen Wang, JeongHee Cho and Changkeun Sung* \\ Department of Food Science and Technology, College of Agriculture and Biotechnology, \\ Chungnam National University, Daejeon 305-764, Korea
}

\begin{abstract}
In order to investigate and evaluate the effects of red deer antlers on hair growth in the full-thickness wound healing model, Sprague-Dawley rats were given incision wounds through the full thickness of their dorsal skin and deer antler was applied for 40 days. At specified intervals thereafter (4, 8, 16, 32 and 40 days), the animals were sacrificed and the wound site skins were excised, processed, and sectioned. At post-injury days 16, 32 and 40, longer and more active new hair appeared around the healing wound of antler-treated skin. Histological studies showed that the antler extract markedly increases the depth, size, and number of hair follicles. Expression of IGF-I (insulin-like growth factor) mRNA was detected by RT-PCR and real time RT-PCR. The result showed that the expression of IGF-I (days 16, 32, and 40) was obviously up-regulated in antler-treated skins compared to control skins. Similar results were seen in the ELISA analysis to quantify the IGF-I expression. These results support the notion that wound healing can cause hair growth by enhancing the expression of IGF-I. Deer antler extract appears to have the potential to promote hair growth and could be used in hair growth products. (Key Words: Hair Growth, Wound Healing, Growth Factors, IGF-I, Wingless-type MMTV Integration Site Family (Wnt))
\end{abstract}

\section{INTRODUCTION}

Hairs are mini-organs that undergo cyclic regeneration throughout adult life, and are an important model for organ regeneration. Each and every hair follicle undergoes a cycle of activity: the hair grows to a maximum length, hair growth ceases, and then the hair is shed and replaced. At the base of this cycle is the ability of hair follicle stem cells to briefly exit their quiescent status to generate transient amplifying progeny, but maintain a cluster of stem cells (Plikus et al., 2008).

The hair-growth process shows that stem cells in the hair follicle "bulge" area generate new lower hair follicles, which, in turn, generate new hair. These same stem cells,

\footnotetext{
* Corresponding Author: Chang-keun Sung. Tel: +82-42-8216722, Fax: +82-42-822-2287, E-mail: kchsung@cnu.ac.kr

${ }^{1}$ Colloge of life science, Huzhou University, Huzhou, Zhejiang 31300, China.

${ }^{a}$ ZhiHong Yang and Author LiJuan Gu contributed to this work equally.

Submitted Jul. 25, 2011; Accepted Nov. 16, 2011; Revised Dec. 5, 2011
}

which play a key role in initiating wound healing, will help lay the foundation for designing more effective woundhealing strategies (Ito et al., 2005).

Hair follicle stem cells are important contributors to the wound-healing process. Hair stem cells located in the follicle bulge are regulated by the surrounding microenvironment. Even minor wounding results in the mobilization of follicle stem cells to generate daughter cells that quickly move into the wound area (Safer et al., 2005). Sun presented the case of a patient in whom active new hair growth occurred around a wound after healing. By their postulation, after wounding has damaged the epidermis and hair follicles, it is possible for them to heal naturally and repair quickly if provided with an appropriate chemical and physical microenvironment (Sun et al., 2009).

Skin wound healing is the process of repairing injuries to the skin and other soft tissues. Many polypeptide growth factors derived from platelets and inflammatory cells are important mediators of tissue repair processes and their functions at the site of injury have been expounded upon (Benn et al., 1996). Various cytokines and growth factors 
also play important roles in hair growth control. IGF-I (insulin-like growth factor) is likely involved in reciprocal signaling according to its expression in the dermal papilla. The biological function of IGF-I in pelage follicles further was examined and it was demonstrated that IGF-I affects follicular proliferation, tissue remodelling, and the hair growth cycle, as well as folliclular differentiation (Weger and Schlake, 2005). It was also reported that IGF-I is a major mediator in all stages of wound healing, including inflammation, and its absence dramatically impairs wound healing across multiple parameters (Kurtz et al., 1999). These observations encouraged us to explore a new material containing the growth factor IGF-I in order to stimulate hair growth in healing skin.

Deer velvet antler, a unique mammalian organ that has an annual cycle of regeneration and grows very rapidly, is proving to be one of the most beneficial products in natural medicine. During antler regeneration, axons navigate in a local environment rich in growth factors and substrate molecules capable of promoting their rapid growth (PitaThomas et al., 2010). The effects of IGF-I and IGF-II on the growth of undifferentiated cells from the growing tip of deer velvet antlers were investigated in in vivo, and these findings indicate that IGF is functionally significant in controlling velvet antler growth (Sadighi, 1994). Higher levels of IGF-I were detected by RT-PCR in the epidermis/dermis layer of antler compared with the other zones demonstrating the presence of growth factors in the growing deer antler (Francis and Suttie, 1998).

Systemic IGF-I concentration has been demonstrated to be associated with seasonal antler development in red deer (Suttie et al., 1989). As the production of antler velvet uniquely involves the generation of hair follicles, Dicks et al. (1996) investigated the presence of IGF-I receptors in the velvet-producing region. IGF-I receptors are present on the hair follicle and sebaceous gland and may be involved in the growth of both seasonally and non-seasonally produced fibre and in the development of antler velvet (Dicks et al., 1996).

Deer antler extract was reported to have effects on wound healing by enhancing the expression of growth factors, including IGF-I, during the healing process (Gu et al., 2008). In this study, we investigate for first time the relationship between wound healing and hair promotion by treatment with deer antler extracts.

Many men and women suffer from hair loss and hair thinning. A better understanding of this process could lead to novel treatments for hair loss and hair disorders, as well as wound healing. The research results may inspire new thinking in the management of alopecia, tissue engineering, and the regeneration of other organs. This information may enable the designing of treatments that enhance the flow of cells from the hair follicle to the epidermis with the aim of enhancing wound healing and treating patients with wounds.

\section{MATERIALS AND METHODS}

\section{Deer antler and topical cream preparation}

Antlers were obtained under conditions approved by the local Animal Ethics Committee and in accordance with protocols approved by the Institute Animal Care. Fresh red deer (Cervus elaphus L. 1758) antlers were collected from an anesthetized four-year old red deer stag from a local deer farm during late spring (Jinshan, Korea). Deer antler topical cream was prepared by mixing into a liposome vehicle (Novasome A, NJ) (Safer et al., 2005). Briefly, fresh tip tissue was homogenized in a Waring blender. The homogenized antler tissues were defatted by extraction with acetone and a 2:1 chloroform-methanol mixture (Ha et al., 2005). The fat-free antler was suspended in $200 \mathrm{ml}$ of 0.02 $\mathrm{M} \mathrm{NaCl}-\mathrm{HCl}$ buffer (pH 6), and incubated at $40^{\circ} \mathrm{C}$ for $8 \mathrm{~h}$ and at $4^{\circ} \mathrm{C}$ overnight. The suspension supernatant was filtered and concentrated by dialyzing in polyethylene 8,000 (Sigma, USA) to $20 \mathrm{ml}$, followed by adding $100 \mathrm{ml}$ of $80 \%$ ethanol for final precipitation. The sample was mixed, allowed to stand for $6 \mathrm{~h}$, and then centrifuged for $20 \mathrm{~min}$ at $10,000 \mathrm{~g}$. The precipitate was dissolved in $5 \mathrm{ml}$ water and mixed in the liposome vehicle. The control topical cream was prepared without any antler extract.

\section{Animals, full-thickness skin wound, and hair-loss model preparation}

Thirty Sprague-Dawley rats (Danhan Biolink Inc., Korea), weighing between 180-200 g, were divided into 2 groups (control and antler treatment groups) with 15 rats each $(n=15)$. Before the initiation of the studies, the rats were acclimatized after arrival for a period of one week for the purpose of habituation before experiments. They were housed in cages with an ambient temperature of $22-23^{\circ} \mathrm{C}$ and given unrestricted food and water. The full-thickness skin wound and hair-loss model was prepared under general anesthesia with ether following Chan et al. (2001) with modification (Chan et al., 2001). The dorsal hair was shaved $(2 \mathrm{~cm} \times 2 \mathrm{~cm})$, and round, full-thickness skin incisions (around $9 \mathrm{~mm}$ in diameter) were made using a puncher on the clipped dorsal skin of the animals (Gu et al., 2008). Approximately $0.2 \mathrm{~g}$ of antler in vehicle preparation was spread gently over the wound side of the rats' dorsal region. The application was performed once daily for 40 days. The hair promotion effect was monitored and photographed during the treatment days by hair length measurements. Measurement tests were performed by three different persons and acceptable data from a minimum of four replicates per person preparation were required. We sacrificed the rats in every group on the same day (days 4, 8, 16, 32, and 40), and collected skin samples. For further 
RNA and ELISA experiments, once sampled, skin tissues were snap-frozen in liquid nitrogen within $20 \mathrm{~min}$ of removal, and stored at $-70^{\circ} \mathrm{C}$. For further Histological analysis, skin samples were fixed in $10 \%$ formaldehyde solution. All animals procedures were approved under the guidelines of the local Animal Care and Use committees.

\section{RT-PCR and real-time RT-PCR}

In order to evaluate the molecular basis of the fast healing/regeneration phenotype in the rat, we examined differential expression of IGF-I genes using RNA extracted from ear tissue. RT-PCR was used to measure the quantity of IGF-I in rat skins during the post-injury days. Total RNA extraction was performed using a modification of the Trizol reagent method according to the manufacturer's instructions (Invitrogen, USA). Complementary DNA was produced from $1 \mu \mathrm{g}$ total RNA using a Maxime RT premix kit (iNtRON, Korea) and the protocol recommended by the manufacturer. Random hexamers were used as primers in cDNA synthesis. Primers were used as previously described in the references (Garcia et al., 1997; Bamman et al., 2001). The IGF-I sense primer was 5'-AAA TCA GCA GTC TTG GAA CC-3' and the antisense primer was 5'CTTCTGGGTCTTGGGCATGT- 3' (Bamman et al., 2001; $\mathrm{Gu}$ et al., 2008). $\beta$-Actin, a ubiquitously expressed gene, was used as an endogenous internal standard to determine the relative expression of IGF-I in different antler tissues. The $\beta$-actin sense primer was 5'-CCC TAA GGC CAA CCG TGA AAA GAT G-3' and the antisense primer was 5'GTC CCG GCC AGC CAG GTC CAG-3' (GenBank Accession No. J00691; Garcia et al., 1997). The cDNA (1 $\mu \mathrm{l})$ was amplified in a $20 \mathrm{ml}$ reaction mixture including $1 \mu \mathrm{l}$ $10 \mathrm{mM}$ dNTP, $1 \mu \mathrm{l} 10 \mathrm{mM}$ forward, $1 \mu 10 \mathrm{mM}$ reverse primers (Genotec Ltd., Korea), $2 \mu$ reaction buffer (containing $80 \mathrm{mM} \mathrm{KCl}, 4 \mathrm{mM} \mathrm{MgCl}$ ), and $0.25 \mu \mathrm{l}$-Taq (5 U/ $\mu \mathrm{l})$.

Measurement of the relative quantities of the cDNA of interest was carried out by real time RT-PCR using SYBR Green PCR Master Mix (Roche Diagnostics, Mannheim, Germany). Assays were performed in a Rotor Gene 2000 Real-time Cycler (Corbett Research, Sydney, Australia). A master-mix of the following reaction components was prepared to the indicated end concentration: $1 \mathrm{ml}$ reverse transcribed cDNA, $1 \mathrm{ml} 10 \mathrm{mM}$ forward primer, $1 \mathrm{ml} 10$ $\mathrm{mM}$ reverse primer (Genotec Ltd., Daejeon Korea), $10 \mathrm{ml}$ SYBR Green I, and $7 \mathrm{ml} \mathrm{dd} \mathrm{H}_{2} \mathrm{O}$. The final volume of the solution was $20 \mathrm{ml}$. The following general real-time PCR protocol for both $\beta$-actin and IGF-I was used: predenaturation at $94^{\circ} \mathrm{C}$ for $5 \mathrm{~min}$, followed by an amplification and quantification program consisting of denaturation at $94^{\circ} \mathrm{C}$ for $20 \mathrm{~s}$, annealing at $55^{\circ} \mathrm{C}$ for $20 \mathrm{~s}$, and extension at $72^{\circ} \mathrm{C}$ for $20 \mathrm{~s}$, repeated 35 times. To further ensure the specificity of the reaction conditions, the melting curve program $\left(72-96^{\circ} \mathrm{C}\right.$ with continuous fluorescence measurements) of the amplified product was run to confirm its homogeneity at the end of individual runs. Data were analyzed using Rotor-Gene analysis software v6.0. RNA quantification was performed using the formula:

Relative mRNA expression

$=1 / 2^{\text {(Ct of IGF-I gene-Ct of } \beta \text {-actin gene) }}$

\section{Histological analysis of hair follicles}

Skin samples were obtained after treatment antler topical cream. Skin fragments collected from the sacrificed rats were fixed in $10 \%$ formaldehyde solution and embedded in paraffin. The fragments were sectioned horizontally and vertically. The sections were stained with hematoxylin and eosin, and examined under light microscope.

\section{Quantification of insulin-like growth factor-I by enzyme-linked immunosorbent assay (ELISA)}

Skin tissues collected from sacrificed rats were homogenized in a urea sample extract buffer containing $1 \%$ SDS, $10 \%$ glycerol, 25 mM Tris- $\mathrm{HCl}(\mathrm{pH} 6.8), 1 \mathrm{mM}$ EDTA, and $0.7 \mathrm{M}$ mercaptoethanol. The homogenate was centrifuged at $12,000 \mathrm{~g}$ for $30 \mathrm{~min}$ and the extracts were used for the ELISA assay (Gu et al., 2008). The ELISA analysis was performed using a commercially available kit (Human IGF-I Immunoassay, R\&D Systems, USA) on tissues extracted and prepared using established protocols. Wells (96 wells/flat bottom) of ELISA plates were coated with $150 \mu \mathrm{l}$ assay diluent and $50 \mu \mathrm{l}$ of the extract and human recombinant IGF-I standard $(6,3,1.5,0.75,0.375$, 0.188 , or $0.094 \mathrm{ng} / \mathrm{ml}$ ), and incubated for $2 \mathrm{~h}$ at $4^{\circ} \mathrm{C}$. Each well was washed three times with the wash buffer. About $200 \mu \mathrm{l}$ IGF-I conjugate was added to each of the wells, which were then incubated for $1 \mathrm{~h}$ at $4^{\circ} \mathrm{C}$. After removal of the conjugate and washing three times with the wash buffer, $200 \mu \mathrm{l}$ substrate solution was quickly added to the wells in the dark. After $30 \mathrm{~min}$ incubation at room temperature, the reaction was stopped by the addition of $50 \mu \mathrm{l}$ stop solution. ELISA plates were read using an Emax Precision Microplate Reader (Molecular Devices, Sunnyvale, CA, USA), and the absorbance of each well was recorded the optical density (OD) at $450 \mathrm{~nm}$ within $30 \mathrm{~min}$. The amount of IGF-I in rat skin was expressed as $\mathrm{ng} / \mathrm{ml}$ using the standard curve.

\section{Statistical analysis}

Statistical analysis was performed using Microsoft Office Excel 2003. For comparison between two groups the Student's t-test was performed. A value of $\mathrm{p}<0.05$ was 


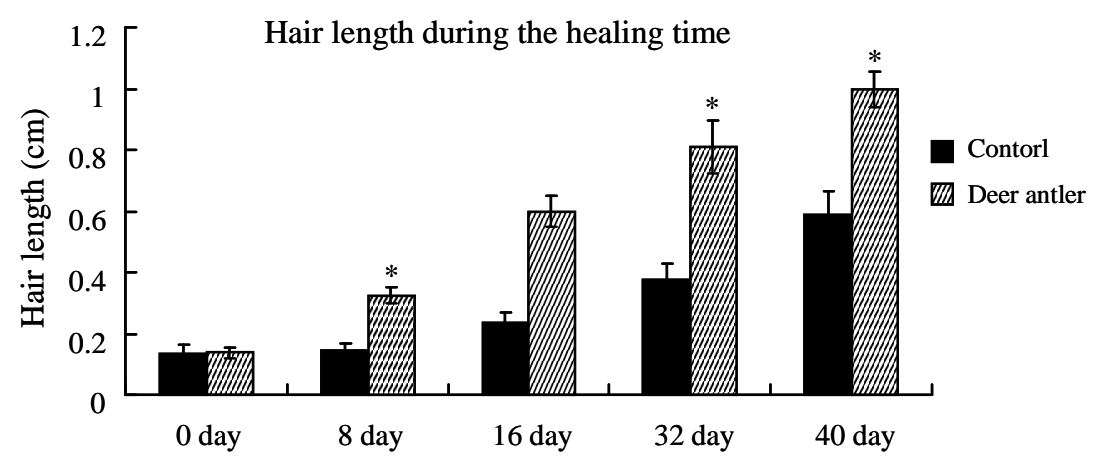

Figure 1. Effects of antler topical cream on hair growth in wound healing rats. During wound healing, the hair growth markedly increased in length on days 16 and 40 compared to the control treatment.

considered statistically significant.

\section{RESULTS}

Hair growth-promoting effects of the deer antler extract

The deer antler extract was superior to control in terms of hair growth promotion. After topical application of the extract onto the backs of rats for up to 40 days, hair growth markedly increased in length on day 16 as compared to the control treatment, resulting in a final hair length of $0.61 \mathrm{~cm}$ relative to the control with a length of $0.22 \mathrm{~cm}$ (Figure 1). The same results can be seen in day 40 ; new hair grew up to $1.12 \mathrm{~cm}$ and covered all of the shaved area in experimental rats. Control rats had rarer and shorter hair growth. These results support the belief that the antler extract induces and stimulates hair growth.

\section{Histological morphology of the epidermis}

To elucidate how the deer antler topical cream affects hair growth, skin sections were histologically analyzed by hematoxylin and eosin staining. We investigated the histological alterations in the skin samples during the hair growth process and investigated the morphology of the epidermis. Histological studies showed that the antler extract markedly increased the depth, size, and number of hair follicles (Figure 2). The overall thickness of the antlertreated skin was thicker than that in control skin on days 16 and 40, which seems to correlate with an increase in the intracutaneous length of hair follicles. As a consequence, the distance between the proximal end of most hair follicles and the muscle layer was clearly enlarged in antler-treated skin as compared to control skin. On day 16, the hair follicles of antler-treated skin appeared to be longer and all hair follicles showed a parallel orientation.

The control skin was thinner. Follicles appeared to be less developed than in deer antler-treated (Figures $2 \mathrm{C}$ and 2D). On day 40, many hair follicles were extraordinarily elongated. The distance between the majority of follicles and the muscle layer was significantly enlarged and some new follicles were stimulated in antler-treated skin (Figure 2F). In the control, the follicles appeared to be less developed (Figure 2E). These results clearly support the belief that antler treatment extracts induce the early onset of anagen and stimulates hair growth. The density and the number of hair follicles are significantly affected by treatment with deer antler extracts.

\section{Expression profiles of IGF-I in the hair-loss skin}

IGF-I is synthesized and secreted by the dermal cells of the skin and by the dermal papillae of hair follicles (Weger and Schlake, 2005). IGF-I has been proven to be an example of the paracrine growth factor, which has hair growth stimulatory activity in organ culture systems (Philpott et al., 1994). In semi-quantitative RT-PCR using $\beta$-actin (Figure 3A) as an internal control, we utilized a set of highly specific primers for the IGF-I gene and examined the expression change of this insulin-like growth factor during the hair growth process. We found that the IGF-I gene studied was expressed at the same level in the hairshaved skin at day 0 . In skin treated with antler ointment, the IGF-I levels were found to be elevated from day 16 after the treatment, as opposed to the levels in the control group (Figure 3A). Expression of IGF-I in the skins treated with antler topical cream were found to continuously increase until day 40 and were significantly stronger than that in the skins treated with the control ointment. This suggests an induction of endogenous IGF-I after the application of the antler ointment.

To quantify the expression of mRNA encoding IGF-I during the hair promotion process, we utilized a real-time PCR system that involved measuring the comparative expression of IGF-I (Figure 3B). The level of expression in the control skin at day 0 was 1.00 , taken as the reference level. We found that the IGF-I gene studied was expressed at different levels during the hair growth process. In particular, the IGF-I gene was most strongly expressed in the treatment skins from day 16 onwards, and levels of IGFI expression were up-regulated compared to the control 

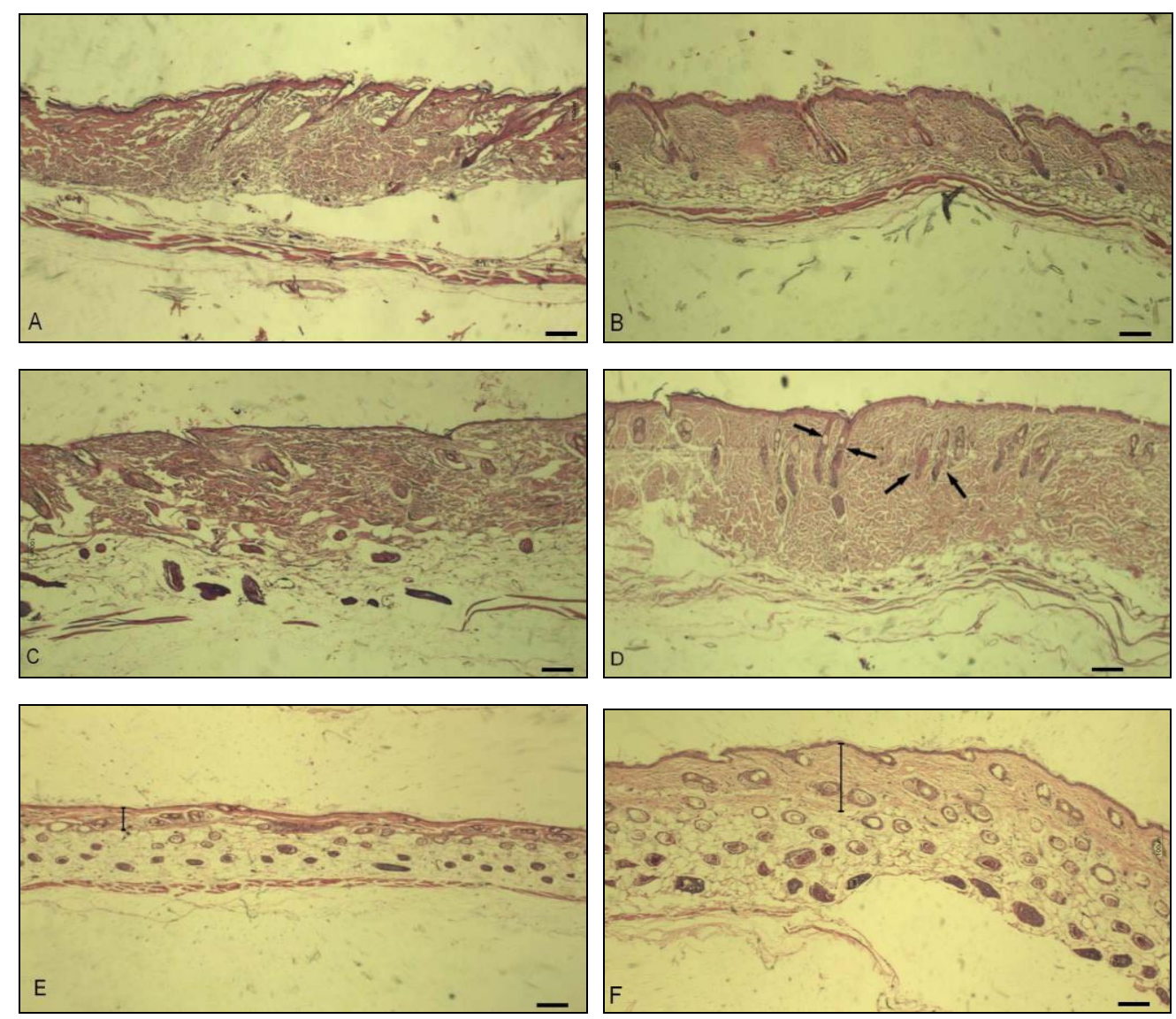

Figure 2. Morphology of wound healing skin. The histology of wounded skin was analyzed by hematoxylin and eosin staining of skin sections. At post-injury day 2, during the first growth phase, no significant difference between deer antler treatment skin (B) and control skin (A) was found. At post-injury day 16, the antler treatment skin was thicker (D) than the control skin (C). New hair follicles occurred in the antler treatment skin and the hair follicles appeared to be longer than those in the control (black arrows). At post-injury day 40, more hair follicles in the antler treatment skin (F) were obviously more stimulated than in the control skin (E). The antler treatment skin was remarkably thicker (F) than the control skin (E) (black lines). In the antler treatment skin, the distance between the follicles and the muscle layer was significantly enlarged. In the control, the skin was thinner and follicles appeared to be less developed. Scale bar $=100$ $\mu \mathrm{m}$.

skins, especially on day 40 . The levels of IGF-I in treatment skins on days 16,32 , and 40 were up-regulated 2.23 -fold (2.748 vs control: 1.235$)$, 1.55 -fold (2.927 vs control: 1.886 ), and 1.81-fold (3.634 vs control: 2.003$)$, respectively.

\section{Enzyme-linked immunosorbent assay and quantification of IGF-I}

In order to compare the IGF-I levels between the deer antler treatment wound skin and control skin post-injury, ELISA was carried out to measure the level of immunoreactive IGF-I in the skins in comparison to human recombinant IGF-I as the standard. A standard curve of human IGF-I concentrations was created according to the serial dilution of standard human IGF-I (Figure 4A). The levels of IGF-I in the treatment skins showed higher quantification than control skins. In particular, the levels of IGF-I in the treatment skins at days 32 and 40 were calculated as $0.7895 \mathrm{ng} / \mu \mathrm{l}$ and $1.1596 \mathrm{ng} / \mu \mathrm{l}$, respectively, which were higher than the concentrations in control skins
$(0.4988 \mathrm{ng} / \mu \mathrm{l}$ and $0.5237 \mathrm{ng} / \mu \mathrm{l}$, respectively) calculated using the standard curve in days.

\section{DISCUSSION}

In a previous report, we demonstrated that deer antler extracts accelerate wound healing by enhancing the expression of IGF-I (Gu et al., 2008). In the present study, deer antler extracts have been proven to have outstanding hair growth promoting effects in a wound healing rat model. Normal hair growth requires the maintenance of a delicate balance between the proliferation and the differentiation of pluripotent epidermal cells in the bulb region of active hair follicles (Millar et al., 1999). The initiation of hair follicle development requires a series of reciprocal inductive interactions between the epithelium and mesenchyme (Hardy, 1992). We found that active new hair growth occurred around the area of wound healing. This suggests wound healing power allowed the hair cloning to create a 


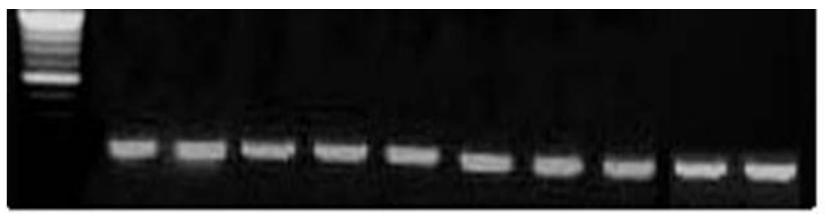

Actin-220 bp

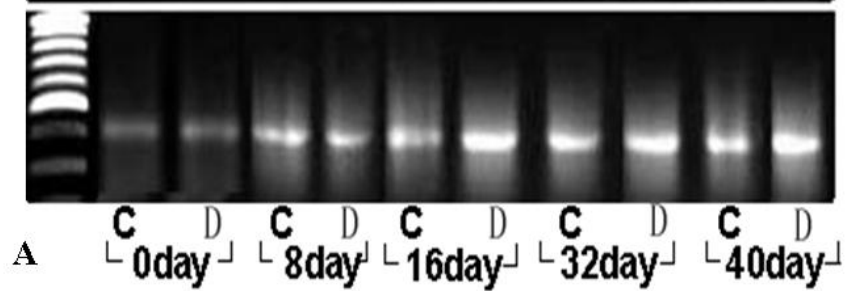

IGF-I-395 bp

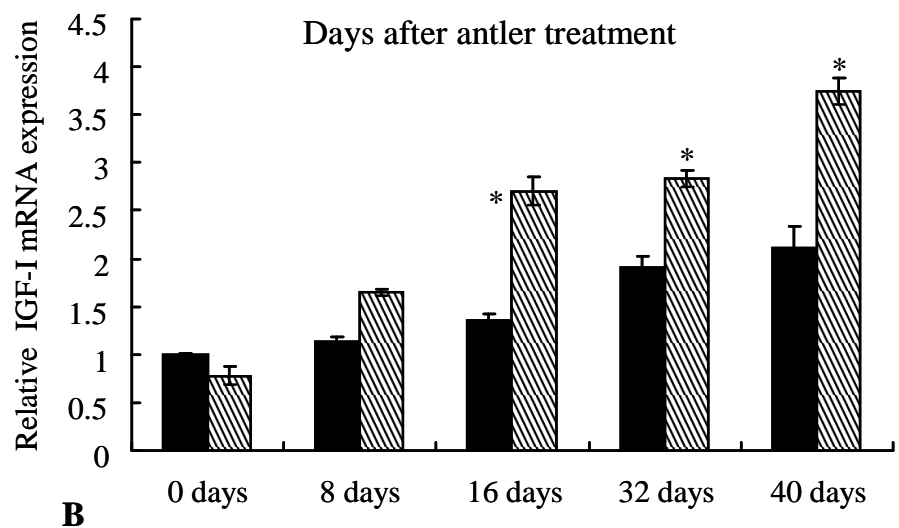

Control

D Deer antler

Figure 3. Comparison between RT-PCR and real-time RT-PCR of IGF-I at indicated the days post-injury. A: RT-PCR was performed on RNA isolated from new hair occurring around wound samples. To determine relative changes of IGF-I in mRNA levels during hair and wound healing development, RT-PCR was performed using specific primers and fractionated on $1.0 \%$ agarose gel. The size of the predicted amplified product for IGF-I (395 bp) is indicated on the right. A 220 bp $\beta$-actin fragment was amplified from the same RT reaction to serve as an endogenous internal control. $\mathrm{C}=$ Control group; $\mathrm{D}=\mathrm{Deer}$ antler group. B: Real-time RT-PCR of IGF comparative expression in the indicated days post-injury.

technique that multiplies the number of hair follicles in an area that had been dormant. The hypothesis is that, after the epidermis and hair follicles have been damaged by wounding, it is possible for them to heal naturally and selfrepair if provided with an appropriate chemical and physical microenvironment (Sun et al., 2009). Hair stem cells located in the follicle bulge are regulated by the surrounding microenvironment and the activation of such stem cells is cyclic (Plikus et al., 2008). Another hypothesis is that wound healing in a mouse model creates an "embryonic window" of opportunity. Dormant embryonic molecular pathways are awakened, sending stem cells to the area of injury. Unexpectedly, the regenerated hair follicles originated from non-hair-follicle stem cells. This suggests that the embryonic window created by the wound-healing process can be used to manipulate hair-follicle regeneration, leading to novel treatments for hair loss and hair overgrowth.

The wound activating Wnt gene, which activates wound healing and hair growth, is a concept that may provide alternative treatments for many people who have hair loss. Millar et al. provided evidence that Wnt genes encode secreted paracrine signaling molecules that regulate cell fate decisions, cell adhesive properties, and proliferation. Although the Wnt family member that directs hair follicle regeneration is not known, Wnt $10 \mathrm{~b}$ is expressed at the necessary time (anagen initiation) and place (follicle epithelial cells) to play a role in hair follicle regeneration (Reddy et al., 2001; Beaudoin et al., 2005).

Wnt signaling can affect the regulation of hair growth and the structure of the hair shaft (Millar et al., 1999). There is increasing evidence that Wnts are necessary for normal skin development (Reya and Clevers, 2005). During the cutaneous wound healing process, Wnt signaling can induce epithelial differentiation (Fathke et al., 2006). It was determined that the expression of Wnt ligands, which typically signal via the betacatenin-independent pathway, is up-regulated in wounds, while beta-catenin-dependent Wnt signaling is activated in the hair follicles adjacent to the wound edge (Fathke et al., 2006). There are several reports about Wnt signaling in the control of hair growth. Wnt 3 and Dv12 have the potential to act in the pathway that regulates hair growth (Millar et al., 1999). Wnt genes encode shortrange secreted signaling molecules that regulate cell fate, 

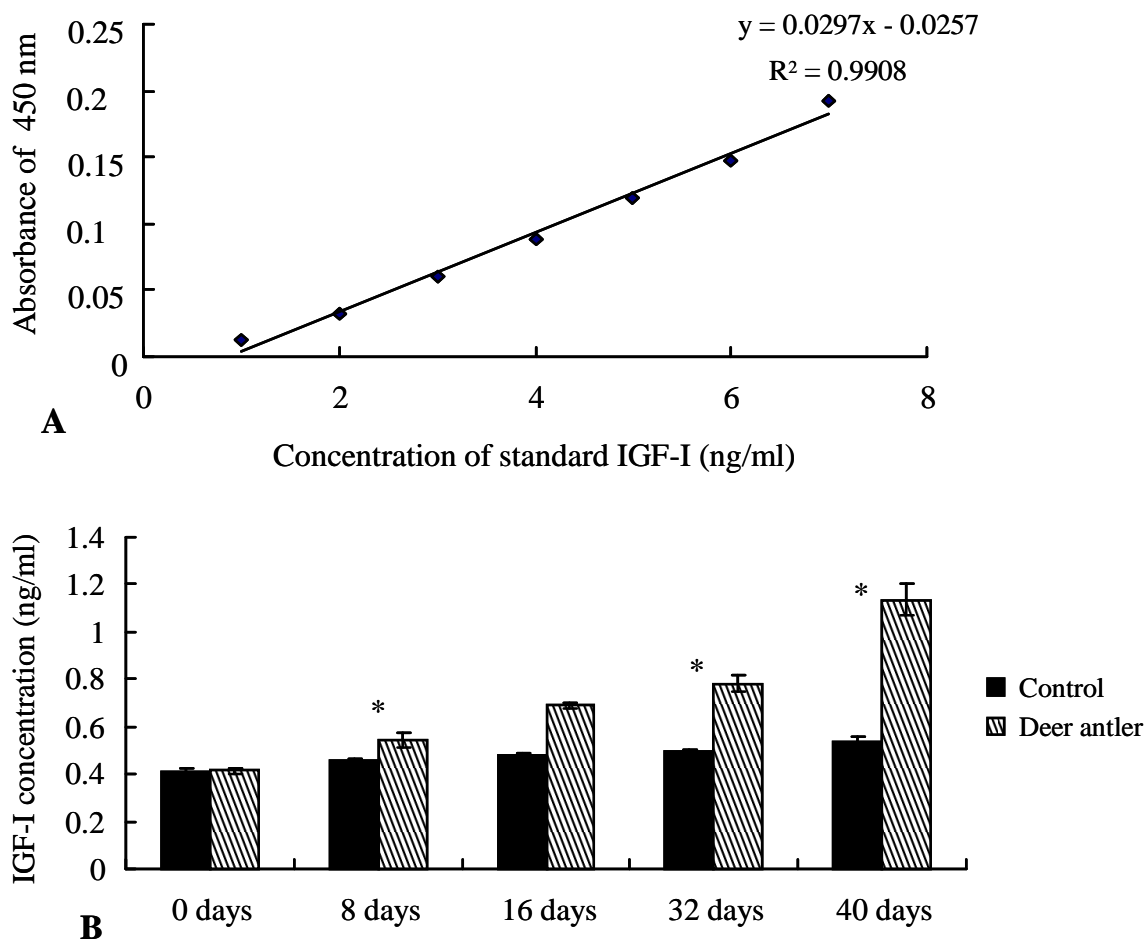

Figure 4. ELISA results comparing the IGF-I levels in deer antler treatment wound skin versus control skin at day post-injury. A: Standard curve for the ELISA. B: The quantification of IGF-I levels was calculated from the standard curve.

adhesion, shape, proliferation, differentiation, and movement, and are required for the development of multiple organ systems (Cadigan and Nusse, 1997; Wodarz and Nusse, 1998). The properties of Wnt proteins, on the other hand, make them excellent candidates as regulators of hair follicle development and hair growth (Reddy et al., 2001). Wnt signals from the follicular epithelium act to maintain the function of the dermal papilla (Kulessa et al., 2000).

It has been recognized for over 30 years ago that minoxidil stimulates hair growth when it was first introduced as a treatment for hypertension. It was noticed that a common side-effect of the minoxidil tablet included the regrowth of hair in balding males. Little is known of the effects of minoxidil on normal human hair growth (Messenger and Rundegren, 2004), but one of the most plausible lines of evidence supports the notion that minoxidil induces cell growth factors, such as VEGF, HGF, IGF-I, and potentiates HGF and IGF-I actions by the activation of uncoupled SUR on the plasma membrane of dermal papilla cells (Otomo, 2002).

Deer velvet antlers have been found to contain a variety of complex elements, including amino acids (almost half of its substance), enzymes, minerals, vitamins, fats, male and female hormones, luteinizing hormone, a very potent growth-promoting hormone known as IGF-I (insulin-like growth factor), epidermal growth factor (EGF), and transforming growth factor- $\beta 1$ (TGF- $\beta 1$ ). These growth hormones and factors have growth promoting actions on the skin. In a previous study, we explored and demonstrated the hypothesis that deer antlers may promote wound repair $(\mathrm{Gu}$ et al., 2008). The epithelium of the wound skin showed smooth regeneration and complete resurfacing within 40 days after the abrasion in antler ointment-treated skin. It has been demonstrated that IGF-I plays a potentially important role in the growth of antlers, which are the only mammalian organs capable of repeated rounds of regeneration (Sadighi, 1994).

The quantitation of the RT-PCR product showed that IGF-I expression after treatment with the deer antler topical cream was higher than that in the control. These results correlate well with the proposed mechanism of rapid skin regeneration in wound healing.

Numerous DP-derived growth factors and cytokines have been implicated as participating in the hair growth cycle as a transition signal and/or hair shaft formation signal, and play important roles in hair growth control (Tang et al., 2003). The anagen term in the hair cycle determines the length and size of hair. It has been reported that some cell growth factors, such as VEGF, FGF-5S, IGF-I, and KGF, induce the proliferation of cells in the matrix, dermal papilla, and dermal papillary vascular system, and increase the amount of extra cellular matrix in dermal papilla, thus maintaining follicles in the anagen phase (Otomo, 2002). IGF-I is one of the major growth regulators for epithelial cells (Rudman et al., 1997). It is produced by mesenchymal cells in a paracrine and autocrine fashion to inhibit apoptosis and promote cell growth (Tang 
et al., 2003). Furthermore, IGF-I appeared to be essential to maintain in vitro cultured human hair follicles in the active, hairproducing state (Philpott et al., 1994). Weger and Schlake (2005) in their study demonstrated that in the transgenic expression of IGF-I in murine skin, some follicles are extraordinarily elongated and hair shafts are longer than their wild-type counterparts. The frequency of IGF-expressing follicles, which represent thin hair follicles decreased and part of the thin hair turned to thicker hair, most likely, the increased thickness of hair shafts is due to IGF-I enhancing proliferation of medulla precursors (Weger and Schlake, 2005).

In this study, we confirmed that deer antler extracts promote hair growth by up-regulating IGF-I. Moreover, we investigated the protein levels of this growth factor, and confirmed that deer antler extracts enhance the expression of IGF proteins. Based on its abilities to stimulate new hair follicles and follicle stem cell proliferation and regulate IGF-I growth factor expression, deer antler extracts are found to be good candidates for the promotion of hair growth. These research results may inspire new thinking in the management of alopecia, tissue engineering, and the regeneration of other organs.

Many people suffer from hair loss despite the development of several medical treatments using plant materials. It is of great importance to develop new and promising treatments for wound healing and hair promotion. The findings in this study illustrate the possibility of a new treatment for human baldness during the wound healing process. If hair growth can be effectively controlled, then people with alopecia can potentially find a cure.

\section{REFERENCES}

Beaudoin, G. M., J. M. Sisk, P. A. Coulombe and C. C. Thompson. 2005. Hairless triggers reactivation of hair growth by promoting Wnt signaling. Proc. Natl. Acad. Sci. USA. 102: 14653-14658.

Benn, S. I., J. S. Whitsitt, K. N. Broadley, L. B. Nanney, D. Perkins, L. He, M. Patel, J. R. Morgan, W. F. Swain and J. M. Davidson. 1996. Particle-mediated gene transfer with transforming growth factor-beta1 cDNAs enhances wound repair in rat skin. J. Clin. Invest. 98:2894-2902.

Cadigan, K. M. and R. Nusse. 1997. Wnt signaling: a common theme in animal development. Genes Dev. 11:3286-3305.

Chan, J. C., D. A. Duszczyszyn, F. J. Castellino and V. A. Ploplis. 2001. Accelerated skin wound healing in plasminogen activator inhibitor-1-deficient mice. Am. J. Pathol. 159:16811688.

Dicks, P., C. J. Morgan, P. J. Morgan, D. Kelly and L. M. Williams. 1996. The localisation and characterisation of insulin-like growth factor-I receptors and the investigation of melatonin receptors on the hair follicles of seasonal and non-seasonal fibre-producing goats. J. Endocrinol. 151:55-63.

Fathke, C., L. Wilson, K. Shah, B. Kim, A. Hocking, R. Moon and
F. Isik. 2006. Wnt signaling induces epithelial differentiation during cutaneous wound healing. BMC Cell Biol. 7:4.

Francis, S. M. and J. M. Suttie. 1998. Detection of growth factors and proto-oncogene mRNA in the growing tip of red deer (Cervus elaphus) antler using reverse-transcriptase polymerase chain reaction (RT-PCR). J. Exp. Zool. 281:36-42.

Gu, L. J., E. Y. Mo, Z. H. Yang, Z. M. Fang, B. S. Sun, C.Y. Wang, X. M. Zhu, J. F. Bao and C. K. Sung. 2008. Effects of red deer antlers on cutaneous wound healing in full-thickness rat models. Asian-Aust. J. Anim. Sci. 21:277-290.

Gu, L. J., E. Y. Mo, X. M. Zhu, X. Q. Jia, Z. M. Fang, B. S. Sun and C. K. Sung. 2008. Analysis of gene expression in four parts of the red-deer antler using DNA chip microarray technology. Anim. Biol. 58:67-90.

Ha, Y. W., B. T. Jeon, S. H. Moon, H. Toyoda, T. Toida, R. J. Linhardt and Y. S. Kim. 2005. Characterization of heparan sulfate from the unossified antler of Cervus elaphus. Carbohydr. Res. 340:411-416.

Hardy, M. H. 1992. The secret life of the hair follicle. Trends Genet. 8:55-61.

Ito, M., Y. Liu, Z. Yang, J. Nguyen, F. Liang, R. J. Morris and G. Cotsarelis. 2005. Stem cells in the hair follicle bulge contribute to wound repair but not to homeostasis of the epidermis. Nat. Med. 11:1351-1354.

Kulessa, H., G. Turk and B. L. Hogan. 2000. Inhibition of Bmp signaling affects growth and differentiation in the anagen hair follicle. EMBO J. 19:6664-6674.

Kurtz, C. A., T. G. Loebig, D. D. Anderson, P. J. DeMeo and P. G. Campbell. 1999. Insulin-like growth factor I accelerates functional recovery from Achilles tendon injury in a rat model. Am. J. Sports Med. 27:363-369

Messenger, A. G. and J. Rundegren. 2004. Minoxidil: mechanisms of action on hair growth. Br. J. Dermatol. 150:186-194.

Millar, S. E., K. Willert, P. C. Salinas, H. Roelink, R. Nusse, D. J. Sussman and G. S. Barsh, 1999. WNT signaling in the control of hair growth and structure. Dev. Biol. 207:133-149.

Otomo, S. 2002. Hair growth effect of minoxidil. Nippon Yakurigaku Zasshi 119:167-174.

Philpott, M. P., D. A. Sanders and T. Kealey. 1994. Effects of insulin and insulin-like growth factors on cultured human hair follicles: IGF-I at physiologic concentrations is an important regulator of hair follicle growth in vitro. J. Invest. Dermatol. 102:857-861

Pita-Thomas, W., C. Fernandez-Martos, M. Yunta, R. M. Maza, R. Navarro-Ruiz, M. J. Lopez-Rodriguez, D. Reigada, M. NietoSampedro and M. Nieto-Diaz. 2010. Gene expression of axon growth promoting factors in the deer antler. PLoS. One. 5: e15706.

Plikus, M. V., J. A. Mayer, D. de la Cruz, R. E. Baker, P. K. Maini, R. Maxson and C. M. Chuong. 2008. Cyclic dermal BMP signalling regulates stem cell activation during hair regeneration. Nature 451:340-344.

Reddy, S., T. Andl, A. Bagasra, M. M. Lu, D. J. Epstein, E. E. Morrisey and S. E. Millar. 2001. Characterization of Wnt gene expression in developing and postnatal hair follicles and identification of Wnt5a as a target of Sonic hedgehog in hair follicle morphogenesis. Mech. Dev. 107:69-82.

Reya, T. and H. Clevers. 2005. Wnt signalling in stem cells and cancer. Nature 434:843-850. 
Rudman, S. M., M. P. Philpott, G. A. Thomas and T. Kealey. 1997. The role of IGF-I in human skin and its appendages: morphogen as well as mitogen? J. Invest. Dermatol. 109:770777.

Sadighi, M. 1994. Effect of insulin-like growth factor-I (IGF-I) and IGF-II on the growth of antler cells in vitro. J. Endocrinal. 143:461-469.

Safer, J. D., T. M. Crawford and M. F. Holick. 2005. Topical thyroid hormone accelerates wound healing in mice. Endocrinology 146:4425-4430.

Sun, Z. Y., J. S. Diao, S. Z. Guo and G. Q. Yin. 2009. A very rare complication: new hair growth around healing wounds. J. Int. Med. Res. 37:583-586.
Suttie, J. M., P. F. Fennessy, I. D. Corson, F. J. Laas, S. F. Crosbie, J. H. Butler and P. D. Gluckman. 1989. Pulsatile growth hormone, insulin-like growth factors and antler development in red deer (Cervus elaphus scoticus) stags. J. Endocrinol. 121:351-360.

Tang, L., O. Bernardo, C. Bolduc, H. Lui, S. Madani and J. Shapiro. 2003. The expression of insulin-like growth factor 1 in follicular dermal papillae correlates with therapeutic efficacy of finasteride in androgenetic alopecia. J. Am. Acad. Dermatol. 49:229-233.

Weger, N. and T. Schlake. 2005. IGF-I signalling controls the hair growth cycle and the differentiation of hair shafts. J. Invest. Dermatol. 125:873-882.

Wodarz, A. and R. Nusse. 1998. Mechanisms of Wnt signaling in development. Annu. Rev. Cell. Dev. Biol. 14:59-88. 